\title{
Penerapan Workbook Matematika Berbasis Kontekstual
}

\author{
Tri Candra Wulandari dan Sri Rahayu \\ Universitas Kanjuruhan Malang \\ Email : fikri.chan@unikama.ac.id
}

\begin{abstract}
Abstrak
Pembelajaran matematika di sekolah dasar masih bergantung pada buku teks dan buku kerja siswa yang juga diterbitkan oleh pemerintah. Secara umum, hal ini tampak lebih sederhana baik dari sisi guru maupun siswa, karena siswa hanya membawa satu buku yang memuat bermacam mata pelajaran. Lemahnya konsep sangat terasa pada mata pelajaran matematika. Secara terintegrasi matematika masuk dalam pelajaran tematik, namun, matematika tetap merupakan salah satu mata pelajaran yang diujikan pada ujian akhir sekolah. Guru yang mempersiapkan ujian akhir harus bekerja keras mengulang konsep mulai dari kelas 1 hingga kelas 5. Oleh karena itu, perlu strategi jitu bagi para guru agar materi yang disampaikan dapat diterima siswa dengan baik. Penelitian ini bertujuan untuk mendeskripsikan penerapan pembelajaran menggunakan workbook matematika kontekstual. Penelitian ini menggunakan metode penelitian kualitatif dengan subjek penelitian 30 siswa SD kelas III di SDN Gadang I Malang. Teknik pengumpulan data menggunakan teknik dokumentasi dan tes. Sedangkan teknik analisis data menggunakan analisis deskriptif kualitatif. Setelah melaksanakan pembelajaran menggunakan workbook, rata-rata ulangan adalah 86,96, dengan skor terendah dan skor tertinggi masing-masing adalah 70 dan 100. Berdasarkan hasil yang diperoleh, workbook kontekstual yang berkaitan langsung dengan tema 7 yaitu sumber energi dapat diterapkan pada pembelajaran matematika di kelas III di SDN Gadang I Malang.
\end{abstract}

Kata Kunci: workbook; matematika; kontekstual

\section{Application Contextual based Mathematics Workbook}

\begin{abstract}
Mathematics in primary schools still rely on textbooks and workbooks students were also issued by the government. In general, it seems simpler both from the teachers and students, because students only carry one book that contains a variety of subjects. Weak concept is very pronounced in mathematics. In integrated math into the thematic lessons, however, mathematics remains one of the subjects tested on a final school examinations. Teachers are preparing for the final exam had to work hard to repeat concepts ranging from grade 1 to grade 5. Therefore, it is necessary for teachers of proven strategies so that the material presented can be accepted students well. This research purposed to describe the application of contextual learning using math workbook. This study uses qualitative research with 30 research subjects third grade elementary school students in SDN Gandang I Malang. Data collection technique used documentation techniques and tests. Data analysis technique used qualitative descriptive analysis. After implementing the learning using the workbook, the average repeat is 86.96 , the lowest score and the highest score each are 70 and 100 . Based on the results obtained, contextual workbook that directly relate to the theme 7 that the energy source can be applied to the study of mathematics the third class at SDN Gadang I Malang.
\end{abstract}

Keywords: workbook; mathematics; contextual 


\section{PENDAHULUAN}

Berdasarkan kurikulum 2013, telah ditetapkan bahwa Matematika di sekolah dasar memiliki buku teks pelajaran untuk siswa dan guru. Secara umum, hal itu sangat membantu siswa dan guru dari segi terpenuhinya sumber belajar bagi siswa dan sumber ajar bagi guru. Akan tetapi, apakah hanya dengan menggunakan buku wajib saja mampu mencapai target ketuntasan yang telah ditetapkan? Fakta yang ada, baik guru dan siswa cukup disibukkan dalam memahami isi buku. Hal ini terjadi dikarenakan buku yang diterbitkan tidak disesuaikan dengan kondisi riil di setiap sekolah dasar. Kondisi riil ini mencakup karakteristik siswa dan tingkat kemampuan siswa sekolah dasar yang tidak mungkin sama di tiap sekolah. Oleh karena itu, perlu strategi jitu bagi para guru agar materi yang disampaikan dapat diterima siswa dengan baik.

Berdasarkan hasil pengamatan peneliti, matematika di sekolah dasar saat ini telah melebur menjadi satu menjadi mata pelajaran tematik. Pembelajaran matematika di sekolah dasar masih bergantung pada buku teks dan buku kerja siswa yang juga diterbitkan oleh pemerintah. Secara umum, hal ini tampak lebih sederhana baik dari sisi guru maupun siswa, karena siswa hanya membawa satu buku yang memuat bermacam mata pelajaran.

Selain melakukan observasi ke sekolah dasar, peneliti juga melakukan wawancara dengan Kepala SDN Gadang 1 Malang saat itu, yang menyampaikan bahwa dengan salah satu dampak penggunaan tematik adalah pada lemahnya pemahaman konsep siswa pada mata pelajaran tertentu. Konsep yang diperoleh sangat dangkal, karena guru hanya memberikan materi sebatas apa yang ada di buku tema saja.

Lemahnya konsep sangat terasa pada mata pelajaran matematika. Meskipun secara terintegrasi matematika masuk dalam pelajaran tematik, namun, matematika tetap merupakan salah satu mata pelajaran yang diujikan pada ujian akhir sekolah. Guru yang mempersiapkan ujian akhir harus bekerja keras mengulang konsep mulai dari kelas 1 hingga kelas 5. Oleh karena itu, perlu strategi jitu bagi para guru agar materi yang disampaikan dapat diterima siswa dengan baik.

Salah satu strategi yang digunakan adalah penggunaan bahan ajar selain buku wajib yang diterbitkan pemerintah, yaitu workbook. Workbook digunakan sebagai salah satu sumber belajar bagi siswa dalam melaksanakan proses pembelajaran di kelas. Workbook merupakan kumpulan dari lembar-lembar kegiatan peserta didik yang berisi tugas yang harus dikerjakan oleh peserta didik. Tugas-tugas yang diberikan kepada peserta didik dapat berupa teori atau praktik (Depdiknas, 2007). Menurut kamus online the free dictionary, workbook adalah: (1) a booklet containing problems and exercises that a student may work directly on the pages, (2) a book in which a record is kept of work proposed or accomplish. (Sa'dijah, 2013).

Sependapat dengan hal tersebut, Adora (2015) menyatakan bahwa Workbook yang dikembangkan di sekolah dasar ini akan mempertemukan siswa tentang apa yang diinginkan siswa dengan apa yang harus dipenuhi siswa berdasarkan tingkat pemahaman siswa. Workbook akan mewadahi siswa dengan karakteristik yang berbeda. Kualitas dan kuantitas waktu yang dihabiskan dalam instruksi yang merupakan 
hal penting dalam pencapaian siswa. Kualitas waktu yang dihabiskan dapat ditentukan oleh guru dan murid, instruksi, aplikasi dan praktek yang menuntut waktu yang cukup untuk memastikan penguasaan siswa pada keterampilan dan kompetensi melalui pemahaman materi.

Mengajarkan matematika dengan mengkaitkan dalam kehidupan sehari-hari merupakan proses pembelajaran kontekstual. Mengajarkan matematika secara kontekstual akan membuat siswa mampu menghubungkan isi dari subjek-subjek akademik dengan konteks kehidupan keseharian mereka untuk menemukan makna (Johnson, 2008). Menerapkan pembelajaran kontekstual tidak terlepas dari bahan ajar yang harus dipersiapkan guru. Pembelajaran kontekstual dengan penyampaian masalah-masalah kontekstual memiliki banyak variasi, termasuk pada pemberian masalah yang diambil dari sumber-sumber lain yang sesuai dengan konteks pembelajaran, membuat masalah dari permainan tradisional dan memodelkan matematika berdasarkan data dari suatu masalah (Wulandari, 2015)

Penelitian ini bertujuan untuk mendeskripsikan penerapan pembelajaran menggunakan workbook matematika kontekstual. Workbook yang telah dibuat merupakan workbook yang semua permasalahannya disesuaikan dengan konteks pelajaran saat ini, artinya workbook yang digunakan berisi masalah-masalah matematika sesuai dengan tema yang sedang disampaikan.

\section{METODE}

Materi yang digunakan dalam penelitian ini disesuaikan dengan tema tematik yaitu tema 7, Sumber Energi. Pada tema 7 ini, kompetensi dasar pada matematika adalah membaca diagram. Oleh karena itu, workbook yang digunakan berisi masalah tentang sumber energi.

Penelitian ini menggunakan metode penelitian kualitatif dengan subjek penelitian 30 siswa SD kelas III di SDN Gadang I Malang. Teknik pengumpulan data menggunakan teknik dokumentasi dan tes. Sedangkan teknik analisis data menggunakan analisis deskriptif kualitatif.

\section{HASIL DAN PEMBAHASAN}

Berdasarkan hasil penelitian, peneliti menemukan beberapa temuan terkait dengan penerapan workbook pada mata pelajaran matematika. Skor rata-rata ulangan siswa sebelum menggunakan workbook adalah 43,5 dengan skor terendah dan skor tertinggi berturut adalah 30 dan 68 .

Setelah melaksanakan pembelajaran menggunakan workbook, rata-rata ulangan adalah 80, dengan skor terendah dan skor tertinggi masing-masing adalah 70 dan 100 . Berdasarkan nilai rata-rata tersebut terlihat bahwa kelas workbook memiliki peningkatan hasil belajar. Siswa mampu menguasai materi dengan baik setelah melaksanakan pembelajaran menggunakan workbook.

Pembelajaran menggunakan workbook lebih baik dari pembelajaran sebelumnya yang hanya menggunakan buku paket tema dan buku kerja siswa. Hal ini sesuai dengan pendapat Dewi (2013) menyatakan bahwa kelebihan workbook adalah pada tampilan tugas yang menarik. Workbook dapat menimbulkan rasa ingin tahu, minat dan perhatian siswa. Materi yang dibahas di dalam workbook relevan dan berguna untuk kebutuhan belajar siswa. Serta tugas dan kegiatan yang bervariasi dapat menampung berbagai gaya belajar siswa yang berman- 
faat. Berikut adalah salah satu tampilan workbook yang digunakan dalam penelitian ini.

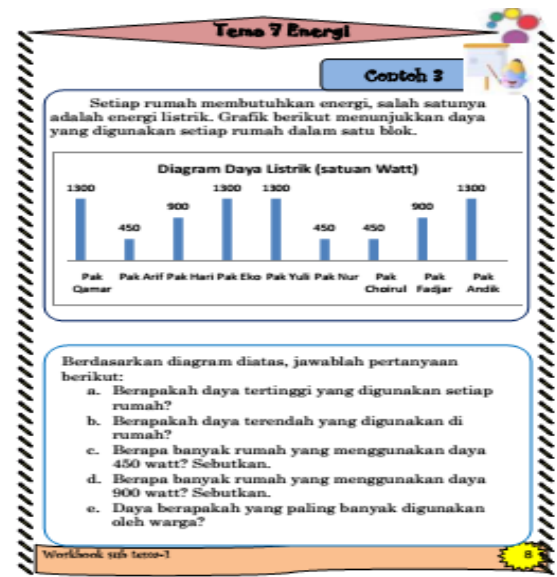

Gambar 1.

Contoh soal pada workbook

Peneliti menggunakan tema yang sedang dibahas sebagai konteks isi workbook. Selain itu sesuai dengan tema yaitu sumber energi peneliti mengaitkan sumber energi dalam kehidupan sehari-hari yang sering ditemui oleh siswa sebagai permasalahan dalam workbook. Berikut adalah salah satu permasalahan dalam workbook.

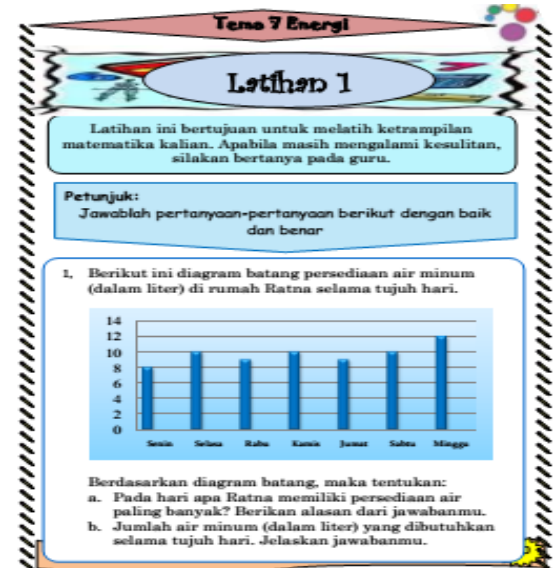

Gambar 2.

Masalah kontekstual pada workbook

Pembelajaran menggunakan workbook diawali dengan penyampaian masalah-masalah yang berkaitan dengan matematika dan sumber energi dalam lingkungan sehari-hari. Setelah guru mengaitkan dengan masalah sehari-hari, guru meminta siswa untuk membaca dengan cermat isi workbook, kemudian meminta siswa menjawab pertanyaan yang tercantum dalam workbook.

Siswa tampak antusias dalam mengerjakan workbook, hal ini tampak dari suasana kelas yang berbeda dengan biasanya. Terdapat perbedaan yang signifikan dalam kelas. Sebelum menggunakan workbook, siswa sering sekali gaduh di kelas dan kurang memperhatikan pelajaran, saat mengerjakan workbook, siswa lebih tenang dan fokus pada workbook masing-masing.

Berdasarkan perubahan sikap dan suasana belajar, hal ini menunjukkan bahwa dengan menggunakan workbook kontekstual mampu membuat siswa menampilkan kemampuan secara individu dan mampu membuat pembelajaran lebih menarik. Hal ini sesuai dengan pendapat Adora (2014) yang menyatakan bahwa one way of maintaining the interest of the learners is to provide them with activities which they could perform individually after being given the proper guidance, instruction as a teaching tool such as workbook or module which could make learning interesting, yang artinya kurang lebih adalah salah satu cara untuk menjaga minat siswa dalam belajar adalah dengan menyediakan kegiatan yang dapat dilakukan siswa secara individual setelah siswa mendapat bimbingan yang tepat sebagai alat pengajar seperti workbook atau modul yang dapat membuat pembelajaran menarik.

Setelah menyelesaikan workbook, siswa peneliti memberikan uji kompetensi. Masalah yang diberikan pada uji kompetensi ini tidak terlalu berbeda dengan masalah yang tercantum pada workbook. Hasil uji kompetensi diperoleh rata-rata 86,96 . Hal ini menunjukkan bahwa pembelajaran menggu- 
nakan workbook kontekstual dapat terlaksana dengan baik.

\section{SIMPULAN}

Berdasarkan hasil penelitian dan pembahasan, workbook kontekstual yang berkaitan langsung dengan tema 7 yaitu sumber energi dapat diterapkan pada pem-

\section{DAFTAR PUSTAKA}

Adora, Nelia M. 2014. Development and Validation of a Workbook in Elementary Mathematics VI. International Journal of Humanities and Management Sciences (IJHMS), Volume 2, Issue 3, ISSN 23204044

Dewi, Ima Melati. 2013. Writing Workbook as Scaffolding Aid for Junior High School Students. Jurnal Pendidikan Humaniora. 1 (3): $284-288$

Johnson, Elaine. B. 2008. Contextual Teaching \& Learning. California: Corwin Press, Inc. belajaran matematika di kelas III di SDN Gadang Malang.

Apabila terdapat peneliti lain yang ingin melakukan penelitian serupa, disarankan agar (1) menerapkan workbook pada materi atau tema lainnya, (2) penyajian kalimat dan isi dalam workbook yang akan digunakan disesuaikan dengan kosakata dan permasalahan yang sesuai dengan tingkat berfikir siswa.

Sunaifah, Ivatus dan Sa'dijah, Cholis. 2013. Pengembangan Workbook Berbahasa Inggris Materi Lingkaran Untuk Pembelajaran Menggunakan Metode Penemuan Terbimbing Bagi Siswa Kelas XI IPA SMAN 4 Malang. Jurnal Pengembangan Workbook Berbahasa Inggris. 13 (83): 775-779

Wulandari,T.C. 2015. Penerapan Modul Kontekstual Untuk Meningkatkan Ketrampilan Matematika dan Berkarakter Mandiri. Prosiding Seminar Pendidikan Nasional. Surabaya, 26 Maret 2015 